\title{
Demos com o colosso em terra: o ocaso de José Bonifácio e a ascensão política de Aureliano Coutinho nas páginas do jornal $A$ Verdade ${ }^{1}$
}

Demos with the colossus on the ground: the decline of José Bonifácio and the political rise of Aureliano Coutinho in the pages of the newspaper "A Verdade" (The Truth)

Julio BENTIVOGLIO•

Resumo: Este artigo analisa a campanha movida por Aureliano Coutinho para destituir José Bonifácio da tutoria do futuro imperador Pedro II, travada a partir de seu jornal $A$ Verdade entre 1832 e 1834. Indica como esta ação foi decisiva para a trajetória política de Aureliano, futuro visconde de Sepetiba, para alcançar a preeminência palaciana na corte imperial brasileira.

Palavras-chave: Brasil Império; Imprensa; Aureliano Coutinho; José Bonifácio; Política imperial.

Abstract: This paper analyzes the campaign started by Aureliano José Bonifácio Coutinho from the tutoring of the future Emperor Pedro II, started through his newspaper "A Verdade" (The Truth) between 1832 and 1834. It indicates how this action was decisive for the political career of Aureliano, future Viscount of Sepetiba, in order to achieve preeminence palace in the Brazilian imperial court.

Keywords: Brazil Empire; Press; Aureliano Coutinho; José Bonifácio; Imperial policy.

Para se chegar ao poder no Rio de Janeiro do século XIX era fundamental uma atuação destacada na imprensa e nas tribunas. Na corte personificava-se essa imagem na qual prevalecia o uso da palavra numa cidade das letras $^{2}$. Ela representava o elo entre a esfera privada dos talentos individuais e o universo público do governo imperial. Boas capacidades de oralidade e escrita eram prerrogativas necessárias para o êxito na carreira política e invariavelmente para o ingresso na nobreza palaciana. Não por acaso escrever em alguma folha ou ainda poder editá-la era condição sine qua non para o desenvolvimento de uma trajetória política. Embora não fossem imprescindíveis, falar e escrever bem eram obrigatórios no reconhecimento das notabilidades. Eram ainda formas incontornáveis de se chegar aos eleitores - assinantes-correligionários - de conviver com os pares, nas cadeiras do Legislativo, nos postos do Executivo e do Judiciário. O binômio referendava as personalidades políticas mais talentosas. Mas a garantia de êxito na carreira exigia que o nome ou a pessoa ultrapassasse os portões de São Cristóvão. Sua fama e sua presença precisavam chegar aos ouvidos do imperador e de seus validos mais próximos. Disso dependeria o reconhecimento nos altos escalões da burocracia imperial. O cume, o primeiríssimo escalão, era representado pela chegada ao Senado ou para o Conselho de Estado. E o imperador não se furtava, uma vez deparado com alguém que tivesse os talentos da escrita, de distingui-lo com alguma medalha, comenda ou título (CARVALHO, 2007). Este artigo mostra como a corte continuava sendo uma referência decisiva nas relações de poder entre a abdicação de D. Pedro I e a constituição

- Professor Doutor - Departamento de História - Centro de Ciências Humanas e Naturais - UFES - Univ. Federal do Espírito Santo - Av. Fernando Ferrari, 514, CEP: 29060-900, Vitória, ES, Brasil. E-mail: juliobentivoglio@gmail.com 
da Regência. Analisa como a proximidade do futuro monarca foi disputada por grupos rivais, ansiosos pelo exercício da tutoria de D. Pedro II. Naquela altura a política imperial não vivia exclusivamente de partidos, habituava-se também às notabilidades palacianas ${ }^{3}$, visto os imperadores sempre manterem ao seu lado pessoas de confiança para coadjuvarem no governo e administração do Império.

Entender esse processo implica vislumbrar a corte como uma hierarquia política que se sobrepunha às demais hierarquias sociais, que se configurava como um princípio dominante e central, uma referência capaz de se exercer em qualquer ponto na vasta cartografia das relações de poder. Ou seja, a monarquia se sustentava sobre os grupos, as expressões regionais e sobre as redes importantes de negócios, sendo, portanto, um constante espaço de disputas. Desde que fosse integrado aquele seleto grupo, era necessário não querer ofuscar o brilho das notabilidades já existentes e reconhecidas, ou caso contrário, seria necessário disputar a preferência no interior da corte. Tal é o caso do embate aqui investigado. Este artigo busca identificar as posições políticas de Aureliano Coutinho em seu jornal A Verdade entre 1832 e 1834 bem como sua campanha vitoriosa contra o então tutor de D. Pedro II, José Bonifácio a fim de ocupar uma posição de destaque na corte imperial brasileira.

Aureliano Coutinho (1800-1855), futuro visconde de Sepetiba, é identificado pelos contemporâneos e pela historiografia como o líder da chamada facção áulica. Ele se tornou, a partir de 1834, em um dos homens mais importantes e influentes dentro do Palácio de São Cristóvão após seu triunfo sobre José Bonifácio (1763-1838). Joaquim Nabuco em Um estadista do Império afirma, por exemplo, que é difícil aquilatar a importância e a singularidade daquela figura imponente (Nabuco, 1897, p. 56). Afinal, se por um lado ele se tornou em um dos validos mais admirados pelo jovem imperador D. Pedro II - que o confessa numa anotação feita na biografia do senador Furtado (Almeida, 1944, p. 27) - por outro, foi também um dos políticos mais criticados de seu tempo. Ao lado de José Bonifácio e Bernardo Pereira de Vasconcelos, talvez Aureliano figure como uma daquelas personalidades mais odiadas e temidas, embora Vasconcelos jamais tenha ascendido à condição de valido do monarca (Carvalho, 1999, p. 34) e Bonifácio tampouco tenha aceitado ou recebido outro título salvo o de patriarca da independência. ${ }^{4}$ Aureliano chama a atenção dos contemporâneos e da historiografia ao liderar uma força política cuja influência oculta foi sentida na corte até meados de 1850. Ou seja, durante mais de uma década, ele e seu grupo estiveram, no entendimento de muitos contemporâneos, envolvidos direta ou indiretamente nos principais eventos da vida política do Império (Silva, 1901 e Otoni, 1916).

Para combater Bonifácio, Aureliano valeu-se, como de costume, do precioso auxílio da imprensa. Ele fundou em 25 de fevereiro de 1832 o jornal A Verdade. Uma folha afinada com os liberais moderados e destinada a guerrear forças políticas rivais. O periódico trazia em seu 
frontispício uma legenda de Boileau (1636-1711): "Rien n'est beau que le vrai, le seul est amable. Il doit réguer par le tout et même dans la fable" ${ }^{\text {.5 }}$ Curioso observar que esse foi o mesmo dístico usado pela folha de Bernardo Pereira de Vasconcelos criada em 1825, O Universal, embora o tivesse corrigido quanto à autoria da frase, pois o mineiro a havia atribuído a Voltaire. O preço da assinatura por um mês custava mil réis e por seis meses cinco mil réis. A folha avulsa era vendida por 80 réis e podia ser encontrada na casa João Pedro da Veiga na Rua da Quitanda e nas casas de Ogier e Batista, na Rua da Cadeia. João Pedro era o irmão de Evaristo da Veiga. Logo de pronto saltam aos olhos as relações existentes entre o jornal e os partidários da moderação. Aureliano já era figura conhecida no Rio de Janeiro no início de uma recente e venturosa carreira política à frente da Intendência de Polícia, recomendado pelo próprio regente, o padre Feijó.

O jornal circulava às terças, quintas e sábados, contendo notícias sobre a corte, sobre as províncias, especialmente a do Rio de Janeiro, dados estatísticos, traduções, trechos de artigos publicados em outros jornais, sobretudo da Aurora Fluminense. Era publicado inicialmente na Tipografia Nacional, mas mudou várias vezes de tipografia. As seções eram divididas da seguinte forma: Interior, Rio de Janeiro - Município da Corte, Exterior, Correspondência, Miscelânea e Variedades. Nesta última seção foram publicados artigos que versavam sobre a cultura do chá, o cultivo do açúcar, a criação do bicho da seda e a produção de queijo de batata. Em Miscelânea eram publicados textos variados que falavam da necessidade de estatísticas, tratavam de questões de filosofia, de moral, falavam do ensino nas escolas de medicina. Em Interior, traziam trechos de relatórios de ministros - em especial aqueles da responsabilidade de Aureliano Coutinho -, publicavam balanços de bancos, dentre outros.

O primeiro exemplar trazia em artigo de primeira folha, redigido por Aureliano Coutinho, a carta de intenções do jornal. Nele o editorialista procurava justificar a motivação moral de seus assinantes e afirmava sua postura patriótica: “amar sua pátria é fazer todos os seus esforços para que ela seja temível de fora e tranquila interiormente. As vitórias e os tratados vantajosos lhe atraem o respeito das nações" (A Verdade 25 de janeiro de 1832, p.1). E sobre seus correligionários indicava que

Uma sociedade de 40 acionistas é a proprietária desta folha, cada um garante a sua existência com uma quantia de $100 \$ 000$ e os lucros ou perdas serão divididos pelos acionistas, alguns de seus membros se encarregam da sua redação ( $A$ Verdade 25 de janeiro de 1832, p.1).

Não foi possível localizar os 40 subscritores, apenas alguns deles, muitos, sugeridos pelas próprias contribuições sob a forma de artigos para o periódico. A intenção do jornal era a de "fazer chegar a verdade, mas onde se espera, a par das calúnias de que abundam os farroupilhas, anarquistas, rusguentos e outros que podem nascer das cavernas dos vícios" (A Verdade 25 de janeiro de 1832, p.1). Verdade e liberdade eram os dois preceitos angulares que, na óptica dos 
redatores, deveriam nortear a ação política, pois

Amamos a liberdade, e tanto que apreciamos as expressões de Bossuet, ' $\mathrm{O}$ amor da liberdade é o mais agradável e o mais doce, e também o mais sedutor e enganador de todos os que tem algum uso na vida humana'. As revoltas, as sedições, o desprezo das leis, tem todos seu pretexto no amor da liberdade $(A$ Verdade 25 de janeiro de 1832, p.2).

E, para que não restasse dúvida quanto à inclinação constitucionalista do jornal, indicava-se de pronto que "a verdadeira liberdade é a submissão às leis" (A Verdade 25 de janeiro de 1832, p.3). E ainda neste primeiro número revelam que o objetivo era pôr fim às discórdias, a fim de "subjugar a facção que tanto tem se esforçado por comprometer e retardar a nossa civilização e prosperidade" - ou seja, combater os exaltados (A Verdade 25 de janeiro de 1832, p.3) ou farroupilhas. Aliás, num dos exemplares há a explicação para a etimologia da palavra farroupilha: cevada pilada em português - no qual se esclarecia que para os exaltados do Brasil não era pilada, mas pilhada, ou seja, roubada ( $A$ Verdade, 28 de fevereiro de 1832, p.4). Nesse mesmo número há um artigo falando das realizações de Saturnino de Sousa e Oliveira à frente da promotoria pública na corte. Saturnino era irmão de Aureliano. Ele seria novamente louvado, em sua perseguição aos perturbadores da ordem pública, os exaltados, em artigo de $1^{\circ}$ de março de 1832. Tempos depois, inverteria-se a situação: Saturnino criou seu próprio jornal, O Sentinela da Verdade, que circulou entre 1835 e 1838, no qual colaborava Aureliano.

Em 1832, a situação política não era das mais tranquilas, como indica Octávio Tarquínio de Sousa,

A vida não era cômoda nos tempos regenciais; por toda parte a agitação, a turbulência, o perigo de subversão da ordem pública, as 'rusgas', os motins, as sedições. Os boatos alarmavam as cidades, sobretudo o Rio de Janeiro; a liberdade de imprensa dava ensejo aos piores abusos [...] quase todos os jornais eram órgãos de mesquinhas paixões (SOUSA, 1981, p. 174).

E para piorar este quadro, nos dizeres de Bernardo Pereira de Vasconcelos:

nossas instituições não estão completas, faltam-nos muitas leis importantes, algumas das existentes exigem consideráveis reformas, e muito há que vivemos sob o governo fraco da regência. Falta-nos um Conselho de Estado, não temos eminências sociais, ou por pobreza nossa, ou porque a inveja e as facções tenham caprichado em nivelar tudo (Apud SOUSA, 1981, p. 177).

Não por acaso, nestes primeiros jornais, os redatores e articulistas buscavam então demonstrar erudição, em constantes referências a Bossuet, Bentham, Mill, Montesquieu e Hume a fim de enobrecer a ilustração de seus articulistas. Suas palavras patenteavam a adesão quase inconteste ao pensamento liberal. N'A Verdade, havia um diferencial: não se furtavam da preocupação com a escassez de estatísticas, perguntando-se 
qual a superfície do Brasil? Quantos habitantes cabem em cada légua quadrada? Quanto valem as propriedades que existem no Brasil, para se proporcionarem os impostos? Quanto se exporta? Quanto se consome? Quantos meninos nascem? Quantas meninas? Quantos morrem (A Verdade, 1 de março de 1832, p.3).

Para não fugir à regra de que as folhas eram criadas para combater outras folhas, A Verdade não cansou de publicar artigos criticando periódicos rivais, pois os redatores de $O$ Ypiranga $^{6}$, do Carijó $^{7}$, do Brasileiro ${ }^{8}$, do Matraca ${ }^{9}$, do Exaltado ${ }^{10}$, da Nova Luz $^{11}$, do Clarim $^{12}$ e outros, que eram repelidos com horror, pois inspiravam homens que ainda achavam "o feroz e sanguinário Robespierre demasiadamente humano [grifos no original]" (A Verdade, 1 de março de 1832, p.1). Até aquele momento, não parecia aos redatores que os caramurus seriam também uma força ameaçadora da ordem. Afinal, muitos dos subscritores e mesmo Aureliano tinham sua origem em família de militares que participaram ativamente da Independência.

Outro assunto que sempre aparecia nas páginas do periódico era sobre o possível retorno do ex-imperador. Em um deles, revela-se que D. Pedro I jamais tentaria voltar ao trono e que essa era uma notícia infundada ( $A$ Verdade, 1 de março de 1832, p.3). Não resta dúvida quanto à vinculação ao grupo moderado, que tinha como liderança inconteste Evaristo da Veiga. A orientação moderada possuía uma direção, uma articulação eficiente, um discurso afinado e uma atuação organizada em seu combate aos restauradores e aos exaltados. É evidente o quanto essa mobilização foi imprescindível para o aprendizado político da época, decisiva na reorientação do sentido das forças políticas, em um momento de consubstanciação dos futuros partidos políticos, por meio da criação da Sociedade Defensora. O fato é que Bonifácio fazia parte do conselho diretor desta sociedade, criada no Rio de Janeiro em 10 de maio de 1831, expressão de que os moderados imprimiram sua direção à agremiação e que Bonifácio afastou-se dela, atuando segundo sua própria consciência ${ }^{13}$.

Voltando ao jornal, na parte de Miscelânea encontramos artigos curiosos, até sobre o divórcio (A Verdade, 3 de março de 1832, p.3). Em Interior também apareceram textos sobre a eleição para o júri e a aprovação do Código Criminal, que foi elogiada. Também há um artigo falando sobre os feitos de Aureliano de Sousa e Oliveira Coutinho junto ao juizado de órfãos da Corte. No ano de 1833, foram publicados artigos sobre a defesa do princípio constitucional, sobre a organização da polícia, tecendo-se comparação com a França e a Inglaterra. E também sobre as escolas médicas.

As agitações políticas eram sempre registradas, sobretudo as insurreições provocadas pelos exaltados, como a referência a um artigo publicado em Tempo ${ }^{14}$, a 6 de março de 1832. Curioso observar que, àquela altura, o jornal já mencionou os Andradas, afirmando: "não podemos deixar em silêncio o sentimento de que somos penetrados quando vemos o sr. Redator do Carijó confundir os Ilustres Srs. Andradas e os Cavalcantis, o Sr. Luiz May, pessoa que temos muita compaixão por suas enfermidades" e prossegue, não sem uma pitada de ironia, "tudo foi feito por esses homens respeitáveis" (A Verdade, 8 de março, de 1832, p.2). Em artigo a 17 de maio, um novo artigo chama 
o Carijó de jornal hipócrita patrocinado por José Bonifácio. Nesse mesmo número, publicou-se a reprodução de uma carta de Vila de Caxoeira na província da Bahia de um leitor revoltado e pedindo para revogar atos de D. Pedro I, "que seria fuzilado em qualquer parte desta província se acaso aparecer" (A Verdade, 8 de março, de 1832, p.3). Dias depois voltariam ao tema, indicando que "D. Pedro já não é nem tem direitos à Coroa do Brasil, nem a quer e provou com a sua espontânea, covarde e precipitada abdicação" (A Verdade, 22 de março de 1832, p.2).

Tinha início a campanha que se realizaria no jornal contra José Bonifácio de Andrada e Silva. Mas, não se pode atribuir exclusivamente a esta cruzada periódica a vitória de Aureliano e a derrocada de José Bonifácio na corte. O peso dos anos, as enfermidades, o desgaste político, a emergência de novas lideranças, dentre outros, são aspectos que também precisam ser considerados. Aos 68 anos, Bonifácio já não era o jovem de antes e viria a falecer, poucos anos depois, em 6 de abril de 1838 na cidade de Niterói. Quando assumiu a tutoria em 19 de agosto de 1831, tinha reatado com o primeiro imperador após o rompimento ocorrido na Assembleia Constituinte e um exílio de mais de cinco anos em Talence na França entre 1823 e 1829 . A situação política era dificílima para D. Pedro I naquela ocasião. Derrotado pela oposição, abdicou e deixou seus filhos Pedro, Francisca, Paula e Januária aos cuidados do Andrada. Desde então os oposicionistas entendiam que Bonifácio era um elemento perturbador na corte de São Cristóvão, favorável à causa restauradora. Logo ele que nunca fora simpático ao meio palaciano. A pronta resistência a sua tutoria começou no Parlamento onde se discutiu a legalidade da nomeação feita por um eximperador. Bonifácio era deputado naquela casa, em substituição ao deputado Honorato José de Barros Paim pela Bahia, diga-se de passagem muito mal-recebido por muitos. Bastaram os levantes de 3 e 17 de abril de 1832 para que um de seus maiores inimigos o acusasse formalmente de participar da conspiração: o próprio regente. Feijó estava convencido de que Bonifácio se envolvia em maquinações contra o regime ao asseverar que "a Quinta da Boa Vista havia se tornado o quartel-general dos conspiradores, que de lá tinham saído duas peças de artilharia e que os empregados do paço estavam entre os revolucionários". (SOUSA, 1972, p. 253). Logo depois o regente exigiu que os príncipes fossem trazidos para o palácio no centro do Rio. Em seguida a Câmara aprovou a destituição do tutor por 45 votos contra 31, mas o Senado por um voto rejeitou-a. De fato, o combate "tenaz, era implacável" ao tutor (SOUSA, 1972, p. 156). A atuação dos irmãos de Bonifácio, Antônio e Martim Francisco ao lado dos restauradores, reforçavam a reação dos moderados a todos eles. Para piorar sua situação, a princesa Paula morreu de varíola. Para Paulo Pereira de Castro,

contra José Bonifácio, muito mais que as suspeitas de restauração, pesavam ódios herdados do grupo de Gonçalves Ledo trazidos por Evaristo; ciúmes palacianos representados por Honório e Aureliano; e, acima de tudo, a transposição para o plano nacional das antigas rivalidades de bernardistas e andradistas por Feijó e os 
companheiros da bancada de São Paulo. Depois do malogro do golpe de 30 de julho [de 1832], só quando a desastrada viagem de Antônio Carlos à Europa deu foros de verdade às acusações já desmoralizadas de seu envolvimento em conspirações restauradoras (CASTRO, 1995, p. 26).

Os vínculos existentes no projeto de ascensão política de Aureliano com a regência e o grupo de Evaristo da Veiga começam a se tornar evidentes naquele momento, rechaçando a volta de D. Pedro I e defendendo o governo Feijó. Enquanto o padre Henriques de Rezende, propunha um projeto que proibia a entrada de D. Pedro I em território brasileiro no Parlamento, o general Cunha Matos estava em Portugal para sondar os planos do primeiro imperador em relação ao Brasil, temendo-se a sua volta. Enquanto o projeto de Rezende era debatido de maneira acalorada na Câmara, Cunha Mattos ouvia do próprio D. Pedro I que aqueles os quais ainda acreditavam que ele pleiteava a coroa brasileira eram um bando de $\operatorname{asnos}^{15}$. Não havia dúvidas de que o grupo se preparava para fixar posição favorável no reinado vindouro. Para isso era crucial defender o governo regencial, mas também se aproximar do futuro imperador que assumiria o trono em breve. Era imprescindível, portanto, conseguir uma posição estratégica dentro da corte com o afastamento de Bonifácio.

Aureliano era um liberal e ao lado de Evaristo da Veiga havia dado combate aos caramurus e aos exaltados. As raízes militares de sua família revelam que tal como o jovem oficialato, ele preferia dar continuidade ao projeto moderado, contrário à restauração de D. Pedro I. Mas o passo decisivo de sua carreira foi ingressar no jornalismo e na carreira pública, inicialmente como juiz em Minas Gerais. Paralelamente a isso sabia que era preciso angariar simpatias dos grupos no poder, palacianos ou não. E o caminho defendido era a preservação do regime monárquico, de modo que o nobilitamento continuava sendo uma meta para ele e muitos daqueles que almejavam integrar a vida política imperial, embora a situação fosse incerta. Nesse sentido, Aureliano aproximou-se e mantinha estreita relação com o visconde de São Leopoldo, com o marques de Barbacena e também o barão do Rio Seco, bem como promovia bailes concorridos em sua residência no Rio de Janeiro. Não por acaso, no dia 10 de março de 1832, menciona-se n'A Verdade o surgimento de o Caramuru $^{16}$, e desde já o combatendo. Em 13 do mesmo mês, a folha mostra preocupação com o envolvimento popular nas insurreições, afirmando-se que "quando o povo domina, nada se faz senão tumultuadamente, sem jamais se consultar a voz da razão; os homens são vendidos aos mais ambiciosos" (A Verdade, 13 de março de 1832, p.2-3).

A campanha contra José Bonifácio esquentou com a publicação de um artigo em 17 de março de 1832, quando os redatores atacam o Carijó e em seguida falam que o tutor havia levado D. Pedro I e as irmãs do Paço para a Quinta da Boa Vista, dizendo que ele pretendia enviar as riquezas e as crianças para o exterior. Especulou-se até que Bonifácio tramava alguma conspiração republicana. Somente no dia 14 de abril, ou seja, mais de um mês depois, Bonifácio voltou com as crianças. Dias 
antes, uma carta perguntava sobre o cargo de tutor de D. Pedro II: se era um quinto poder independente ou se deveria obedecer à regência (A Verdade, 10 de abril de 1832, p.2). E prossegue

como pois o sr. José Bonifácio desobedeça formalmente as ordens da Regência e está em São Cristóvão dando ordens contrárias às do governo, e este não faz executar as suas, não satisfaz aos votos do povo e Guarda Nacional quanto ao regresso de S. M. para o Paço da cidade? [...] o sr. José Bonifácio tem em São Cristóvão duas pequenas peças de artilharia carregadas. Ass. O Convencido ( $A$ Verdade, 10 de abril de 1832, p.2).

Aparentemente, os problemas de Bonifácio ampliaram-se quando ele afastou Mariana Carlota de Verna Magalhães Coutinho, camareira-mor nomeada por D. Pedro I para cuidar dos príncipes e princesas imperiais. Ela havia sido responsável pelos estudos iniciais de D. Pedro II e era considerada como uma segunda mãe pelos filhos de D. Pedro I. Ao entrar em atrito com ela, que tinha parentesco com a família de Aureliano Coutinho, José Bonifácio ganhou ainda mais inimigos, bem como permitiu que questões internas relacionadas ao cotidiano na corte, envolvendo sua tutoria, viessem a público, colaborando para sua queda iminente. Não por acaso, após a derrota e remoção de Bonifácio da tutoria, Aureliano escreveu a ela, dizendo: "Parabéns, minha senhora; custou, mas demos com o colosso em terra" [grifos meus] (Apud SOUSA, 1972, p. 259).

Antes que isso ocorresse, foi preciso manter a campanha contra José Bonifácio. No dia 19 de abril voltam à carga, em longo artigo no qual são feitas novas censuras e reservas contra o tutor. No dia 21 são bastante explícitos:

\begin{abstract}
logo sem a suspensão do tutor nada se pode colher sobre o principal cabeça dessa horrorosa conspiração; eu desejo ver o sr. José Bonifácio justificado da gravíssima presunção de conspirar contra o seu pupilo, creio que são as suas imprudências que causam essa presunção, os indícios, mas importa muito à sua honra que o suspendam, ou que ele se demita para que não se diga que o temor e a influência do seu emprego deu causa a nada se provar contra ele. O Anti-Caramuru ( $A$ Verdade, 21 de abril de 1832, p.4).
\end{abstract}

No dia 24, mais ataques:

apontam-se gastos de $12 \$ 000$ para tratamento de José Bonifácio, 30\$000 com a nomeação da camareira-mor, sendo que pelo artigo 4 da lei ele não poderia nomear empregados e ter gasto $800 \$ 000$ além dos dois contos estipulados em lei, com suas funções e nomeando um tesoureiro (A Verdade, 24 de abril de 1832, p.2).

Naquele mesmo dia, às 8 da manhã o intendente de polícia tinha ido até o Paço da Quinta da Boa Vista e apreendido alguns objetos: um barril de pólvora, mais de 80 cartuchos de artilharia, que poderiam "fazer voar o Paço e todos que nele estavam". José Bonifácio alegou desconhecer a existência desses objetos e ainda de 35 baionetas, 11 talabartes, 34 bandoleiras, 296 balas de espingarda e 34 pedrerneiras. Depois o jornal apresenta ainda algumas falas de Antônio Carlos 
Ribeiro de Andrada, irmão de José Bonifácio, em que maldiz o governo, fala de sua fraqueza e iminente ruína (A Verdade, 28 de abril de 1832, p.2). Não resta dúvida quanto ao estratagema de incutir nos leitores reservas aos Andrada, de colocá-los contra o tutor e contra uma família que tivera grande prestígio na corte. Detalhe importante seria saber de onde essas informações partiam. Certamente havia alguém, dentro do Paço, solidário com Mariana Coutinho, um desafeto de Bonifácio, que alimentava os opositores do tutor.

Fazendo a radiografia da imprensa amiga, de orientação moderada, os redatores apontam que estavam ao lado do governo Aurora ${ }^{17}$, Astréa ${ }^{18}$, o Independente ${ }^{19}$, A Verdade, o Diário do Governo ${ }^{20}$, o Grito da Pátria ${ }^{21}$, O Brasileiro ${ }^{22}$, O Homem e a América ${ }^{23}$, O Mensageiro $^{24}$, o Simplício da Roça $^{25}$, o Recopilador ${ }^{26}$ e além disto, o Jornal do Commércio e o Correio Mercantil ${ }^{27}$ (A Verdade, 24 de março de 1832, p.1). Feijó foi alvo também de defesa por parte do jornal em 31 de março de 1832. Em 21 de abril, foram publicados textos que mostram a lealdade das tropas ao governo, à independência e à Constituição, assinados por João Paulo dos Santos Barreto. Este mesmo João Paulo, amigo próximo de Aureliano, foi o organizador do gabinete de 1846, ano em que também acumulou as funções de mordomo-mor em São Cristóvão. Ao que tudo indica sua queda e a do ministério naquele ano, bem como o não preenchimento deste cargo nos anos subsequentes, revelam a perda de seu prestígio, bem como o recrudescimento da facção áulica de Aureliano.

Revelando as relações entre estes áulicos, a folha publica em 29 de março de 1832 o ofício do “digno patrício" Francisco de Salles Torres Homem, aprovado pelo conselho da Sociedade Defensora, que "realçou ideias já na sã política, dignas de serem defendidas por todo Brasil” em segunda página. Em 31 de março, mostrando afeição por alguns validos do Primeiro Reinado, a folha lamenta, a ausência do visconde de Cairu da comissão escolhida para confeccionar o Código Comercial, cujo filho era amigo íntimo de Aureliano. Aqui ressalta aspecto decisivo da atuação política de Aureliano: acolher neófitos aspirantes à nobreza palaciana e resguardar membros antigos da mesma, órfãos da Corte de D. Pedro I. Estratégia hábil para se aproximar da nobreza, da qual ele ainda não possuía título algum.

Nas páginas d'A Verdade patenteia-se a crise do período. Muita boataria sobre golpes, atentados à Regência, volta de D. Pedro I, quarteladas, atentados feitos por exaltados, conspirações caramurus, surgiam a todo instante nas colunas do jornal. Há também, um estranho manifesto do povo e da tropa do Rio de Janeiro em que no final pedem Antônio Carlos, Manoel Carvalho Paes Andrade e João Pedro Maynard como Regentes (A Verdade, 7 de abril de 1832, p.1), que causou grande incômodo político, pois afrontava o Parlamento e a Regência, pedindo a destituição e exílio de várias personalidades. A resposta de Feijó foi enérgica, pedindo retratação pública dos subscritores e ameaçando com prisões.

Uma notícia que traz importante subsídio para pensar as estratégias de atuação do grupo de 
Aureliano apareceu no dia 21 de abril de 1832. Aureliano procurou junto às lideranças militares, sobretudo aquelas próximas de sua família, garantir a ordem constitucional, para se evitar a insubordinação de partes da tropa, motins e distúrbios, frequentes naquele momento, evitando fragilizar o regime. E a aliança com os militares garantiria a manutenção da ordem, sendo-lhes franqueada a proximidade com o imperador, que sempre viu com bons olhos os serviços prestados por aqueles que, desde o Primeiro Reinado, asseguraram a continuação do regime monárquico, permitindo-lhe subir ao trono. Não por acaso, muitos dos fidalgos e gentis-homens da Câmara Imperial eram militares, muitos deles haviam estado ao lado de seu pai. Isso revela, de certo modo, o elo bastante antigo entre cavalaria - organização militar - e nobreza.

Outro detalhe significativo parece evidenciar um "racha" nas altas patentes militares, no oficialato mais afeiçoado a D. Pedro I, que constituíra a Sociedade Conservadora da Constituição Política Jurada no Império do Brasil criada em 1832 por civis e militares, inspirando-se nas legiões romanas, com círculos de 34 associados, com um chefe nomeado presidida pelo marechal Antônio Manuel da Silva Sampaio, e como diretor Antônio Carlos de Andrada (WERNET, 1978, p. 10). Ao que tudo indica, o grupo de Aureliano, também com raízes na força militar palaciana, adotou outra postura, mais afinada aos moderados, defendendo a legalidade e a continuidade da regência, preferindo ingressar nas fileiras da Defensora. Se dentro da corte existiam naquele momento muitas fissuras nas forças palacianas, em que alguns vértices eram Barbacena, Holanda Cavalcanti, Pedro de Araújo Lima, Calmon Du Pin e Bonifácio dentre outros, nos quartéis não era diferente, onde fica nítida uma divisão entre os militares contrários e favoráveis à restauração.

A partir de 24 de abril, o jornal passou a ser vendido em mais lugares, nas casas de João Pedro da Veiga na rua da Quitanda, 202; Domingos Antônio da Silva, rua de São Pedro, 199; João Batista, rua da Cadeia, 114 e Agostinho de Freitas Guimarães, rua Sabão 48. Pelo que se depreende, havia boa acolhida para a folha, visto constantemente aumentar seus pontos de distribuição. Em primeiro de maio o jornal retoma as acusações contra o tutor e o tesoureiro que foi nomeado a $800 \$ 000$, o fiel do tesouro com $600 \$ 000$ e o revisor de contas a $400 \$ 000$ por ano. O Jornal do Commercio confirma esta notícia em sua edição do dia 3 de maio. Mais acusações a José Bonifácio são feitas na página quatro, com a reprodução de um artigo que havia saído na Astreia. Dias 10 e 12 de maio, novos artigos contrários ao tutor. Dia 15 e 17 ataques são desferidos contra os caramurus. A partir de então os articulistas se convenciam de que, ao lado dos exaltados, os restauradores eram uma força desagregadora que precisava ser combatida. No dia 26 de maio, são várias as críticas desferidas a Martim Francisco e a José Bonifácio, acusados de arbitrariedades e perseguições. Ali, um longo artigo de Paulo Barbosa - futuro mordomo-mor de D. Pedro II e braço direito de Aureliano na corte - em que diz por ter sido nomeado moço do Paço, não ser ingrato nem ao bispo de Anemúria, nem aos Andradas com quem diz ter falado apenas duas vezes 
e para que se não diga que sou injusto, diria que estimo e respeito muito as qualidades literárias destes senhores e as de incorruptibilidade, mas que sinto ver que não empregam seus talentos no bem público, e que um espírito de vingança os desvia do trilho, porque desejava vê-los seguir, logo não sou nem grato, nem ingrato aos senhores Andradas (A Verdade, 26 de maio de 1832, p.2).

No dia 22 de maio, censura-se Holanda Cavalcanti que pedia para os políticos não aceitarem as pastas do Ministério para fazer cair a regência de Feijó. Estava claro que ele, ao lado de Bonifácio, era um dos elementos rivais a Aureliano. Entre as pessoas que escreveram no jornal, como Paulo Barbosa, Aureliano, José Rodrigues Moncorvo - cunhado de Aureliano -, Torres Homem, Francisco Carneiro de Campos, Santos Barreto, Ferreira de Melo, Manoel Soares Inácio Lisboa, Manoel Francisco de Azevedo, Diogo Soares Bivar, João Antônio Rodrigues de Carvalho, Manoel Odorico Mendes, José Ferreira Campos e também Antônio Pereira Rebouças, é possível depreender que fossem parte dos 40 responsáveis pela folha e seus primeiros subscritores. E ainda que num futuro próximo praticamente todos eles integrassem a facção áulica.

No dia 5 de junho, mais críticas a Bonifácio. No dia 16 são publicados longos discursos no Senado proferidos por Barroso e por José de Alencar. E também é elogiado o projeto de Montezuma sobre a naturalização dos estrangeiros nos dias 23 e 26 de junho. Nos dias 28 e 30 de junho José Bonifácio é associado aos caramurus, sendo apontado como um dos seus líderes, reproduzindo-se trechos extraídos do jornal Novo Farol Paulistano. Nos dias 5, 7 e 10 de julho, A Verdade acompanha os desdobramentos do parecer da comissão de Constituição e Justiça sobre a substituição do tutor de D. Pedro II. Ali se revela que "não é portanto conveniente ao senhor José Bonifácio continuar, nem à Nação que ele continue [...] ninguém ignora que o Paço ferve com uma intriga e que S. Ex. protege certos indivíduos contra outros" E continua, "muito se pergunta quem será o tutor, e a maior parte dos votos que temos ouvido recaem ao Exmo. Sr. Marquês de Itanhaém [...] outros põem suas vistas no Exmo. Visconde de Congonhas [...] fala-se também no sr. Bispo, no sr. Marquês de Palma" (A Verdade, 28 de julho de 1832, p.2). No dia 12 de julho, mais críticas em um longo texto sobre a tutoria e a nomeação do tutor feita por D. Pedro I.

No dia 19 de julho, novos ataques a Bonifácio, que não foi à sessão do Parlamento para se defender das críticas que vinha recebendo. No dia 21 de julho o jornal publicou as sessões do Senado sobre a substituição do tutor. Caravelas, Vergueiro e membros da comissão endossaram a substituição, mas vários senadores foram contrários. O parecer foi reprovado por um voto em 26 de julho; Almeida Albuquerque e Cairu votaram contra, Borges também. Longo artigo falando sobre o debate ocorrido naquela seção e um outro mais contra o tutor. Na seção de Correspondências do dia 24 de julho foi publicada uma carta contra José Bonifácio onde se lembrava a fala de Vergueiro no Senado quando revelou que de acordo com o decreto de nomeação de Bonifácio, dizia-se "a Assembléia... o removerá quando julgar conveniente". Em 28 de julho A Verdade publicou os 
nomes de deputados e senadores que foram favoráveis à destituição de José Bonifácio, incutindolhes o mote de patriotas. Estava claro que a regência de Feijó e os moderados tinham no Senado um forte centro de oposição. Foi então que surgiu a ideia equivocada para o golpe, tramado por Feijó e pelo Gabinete, que pediria demissão coletiva no intuito da Câmara se converter em Assembleia Nacional. A meta era derrotar de uma só vez o Senado e os opositores ao regime. No momento crucial, porém, Honório Hermeto mudou de ideia e o golpe foi frustrado. Todo o gabinete foi substituído e o grupo de Vasconcelos retornou ao poder.

Em 7 de agosto o jornal noticia o pedido de demissão de Aureliano da Intendência de Polícia da Corte (A Verdade, 28 de julho de 1832, p.2). Logo depois, em três edições é publicado o longo discurso de Honório Hermeto Carneiro Leão, nos dias 16, 18 e 21 de agosto. Estava claro que se buscava a união das altas expressões da ala moderada, Evaristo não queria perder o apoio de Honório. Novamente $A$ Verdade volta à carga, atacando Bonifácio e Holanda Cavalcanti, a frente da pasta da Fazenda, de uma só vez. Holanda pediu demissão no começo de setembro. Em uma carta publicada em 6 de setembro acusam-se alguns serviçais e o tesoureiro-mor de darem dinheiro a caramurus. Mais complexa ia se tornando a intriga que incriminava o tutor, bem como surgiam indícios seguros de que ele não se comportava adequadamente no cargo.

Revelador é um artigo sobre os partidos, pois Aureliano e muitos integrantes da facção áulica não se vincularam aos partidos políticos posteriormente. Segundo ele,

o espírito de partidos é sem dúvida o maior fragelo [sic] que pode pesar sobre um povo: e se ele é funesto para uma nação já veterana na carreira da liberdade, como não o será para com aquela que de pouco lança os primeiros fundamentos, ainda mal combinados para paz e prosperidade (A Verdade, 25 de setembro de 1832, p.2).

Mais críticas a Montezuma e também ao Senado vitalício no começo de outubro e também outras a José Bonifácio; a 20 de outubro, por exemplo, existe um texto pormenorizando os gastos e o mau uso da verba por parte do tutor, que sequer inventariava em um livro adequadamente a contabilidade. Formalizou-se uma petição de alguns senadores que exigiam: $1^{\circ}$ que as contas do tutor fossem apresentadas e aprovadas na Assembléia; $2^{\circ}$ que o tutor remetesse relatório a ambas as Câmaras no começo de março com receita, despesas e tabelas; $3^{\circ}$ que gastasse apenas $400 \$ 000 \mathrm{em}$ esmolas; $4^{\circ}$ que permanecessem apenas mordomo, tesoureiro, fiel e escrivão; $5^{\circ}$ que fossem avaliadas as joias e preciosidades da Casa Imperial; $6^{\circ}$ que se arrendassem as Feitorias de Santarém, Bom Jardim e Piripiri; $7^{\circ}$ que se indicasse o terreno para o palácio na fazenda Santa Cruz; $8^{\circ}$ que fossem arrendadas as candelárias de S. João de Barueri, Corgo da Anta e Fazenda São José; $9^{\circ}$ que depois de arrendadas fossem vendidos todos os escravos e o produto seguisse para os cofres públicos; $10^{\circ}$ que a candelária da Cachoeira de Campos fosse entregue à Junta da Fazenda; $11^{\circ}$ que o tutor cobrasse as dívidas dos foros da fazenda de Santa Cruz; $12^{\circ}$ que se examinassem os títulos 
das doações de casas feitas nos tempos de D. João VI; $13^{\circ}$ que se responsabilizasse o administrador da Quinta do Caju; $14^{\circ}$ que fossem vendidos os ornamentos da relação; $15^{\circ}$ que removessem os superintendentes das candelárias e fazendas; $16^{\circ}$ que se indenizassem as princesas; $17^{\circ}$ que remetesse as contas do mordomo-mor, e, $18^{\circ}$ que empregasse os saldos de S. M. I., na compra de objetos necessários para sua dignidade e decoro. Assinaram o documento José Inácio Borges, visconde Alcântara, marquês de Marica, Manoel Castro e Silva, e A. P. da Costa Ferreira em 8 de outubro de 1832. Pairavam dúvidas sobre a honestidade do patriarca, contudo, é curioso observar que Bonifácio morreu aos 75 anos, em 1838, numa casa modesta na Ilha de Paquetá, aparentemente pobre, tendo em vista seu testamento, embora possuísse mais de 6 mil livros. De acordo com o testamento, deixou para sua filha Narcisa um sítio em Outeirinhos, a pequena fazenda Montesserrate em Parnaíba, parte de um engenho de açúcar em Piracicaba, a casa em Paquetá e quatro apólices no valor de 1:400\$000. Como se observa, não era tão desprovido de recursos como parecia. Desde 1829 recebia uma pensão de 4 contos de réis do governo, mas não havia quitado a dívida com Meneses Drumond que havia pago sua vinda e de sua mulher da França para o Brasil de 4:218\$000 (SOUSA, 1972, p. 263).

Pressionado, José Bonifácio apresentou no dia 10 de outubro um relatório de sua tutoria, referente ao período de agosto de 1831 a março de 1832, no qual indica ter feito gastos da ordem de 105:179\$846 (A Verdade, 23 de outubro de 1832, p.2). O relatório continuou a ser publicado no dia 25 de outubro, porque no dia 17 de novembro o jornal publicou em sua primeira página a notícia bombástica de que a facção andradista desejava derrubar a Regência. A campanha de difamação contra o tutor ganhava maiores proporções e a situação do Andrada ficava cada vez pior perante a opinião pública. Era acusado de atentar contra o governo, de incitar a anarquia, de reunir armas e munições no palácio, de planejar contra os herdeiros do trono imperial.

Em 3 de janeiro de 1833, há uma carta do visconde de Santarém pedindo a D. Pedro I para evitar uma guerra civil no país e dizer claramente que não pretendia voltar ao Brasil. Era mais uma vez o combate aos restauradores, embora não fossem abandonadas as críticas e a ironia em relação ao tutor, como no artigo publicado dois dias depois no qual um missivista, chamado Padre Mestre, dizia que D. Pedro II não tinha mais direito ao trono e que se poderia escolher um outro monarca, e o articulista, em tom irônico diz: quiçá um Andrada (A Verdade, 5 de janeiro de 1833, p.3).

A relação com os validos da corte é evidenciada através da publicação da lista das nomeações dos camaristas que tomaram posse em 1833 (A Verdade, 8 de janeiro de 1833, p.2). E a defesa do ministério também, com o elogio à atuação do ministro da Justiça José Martins da Cruz Jobim (A Verdade, 10 de janeiro de 1833, p.1). Em 13 de janeiro, o jornal conclama os moderados à ação, a se unirem no combate aos radicais, visto creditar que "os Exaltados de encomenda, esses escravos de D. Pedro I, improvisados em demagogos" (A Verdade, 13 de janeiro de 1833, p.2) preparavam 
futuras conspirações.

No dia 24 de janeiro de 1833 foi publicado um abaixo-assinado em que povo e tropa do Rio de Janeiro apresentavam os nomes dos inimigos da nação brasileira, ou seja, exaltados e corcundas, em mais de 4 páginas -. No dia 31, na edição de número 137 na seção de Correspondências, três cidadãos esclarecem não se incluir junto aos relacionados na folha contra a nação brasileira, pedindo retratação.

Neste mesmo ano de 1833 alguns liberais tentaram convencer a princesa Januária de assumir a regência, e das páginas do Atlante Justiniano José da Rocha asseverou que se tratava de iludir uma princesa incauta e inexperiente. Identificava-se, portanto, mais uma força que procurava projetar-se no espaço da corte e do governo: os januaristas. Por trás dela pairavam as influências de Holanda Cavalcanti e de seu grupo palaciano. E parece que tanto Vasconcelos quanto Aureliano não se importaram com aquele plano, embora Sepetiba tenha ficado em silêncio a respeito, ao contrário de Vasconcelos. Naquele momento, ainda sem pertencer à nobreza, penso que a postura de Aureliano foi defensiva diante da influência palaciana de Holanda Cavalcanti. Posteriormente, a disputa entre eles por maior espaço na corte foi visível, ampliando-se as divergências.

Diante de frequentes ataques, a imagem do tutor Andrada já estava demasiado comprometida. Segundo nos informa Otávio Tarquinio,

Os moderados acusavam José Bonifácio de manter o menino imperador [e suas irmãs] num regime de reclusão e a Aurora, por ocasião dos ataques nervosos de que o mesmo fora vítima, em outubro de 1833, filiava-os 'à viciosa educação do augusto menino, temperamento débil, cercado de pavores reais ou imaginários, não se atrevendo o tutor a levar o menino a passear' (SOUSA, 1981, p. 144).

Isso aparece no jornal, em 16 de fevereiro, quando um longo artigo volta a detratar os Andrada e alude à prisão dos príncipes, recolhidos e o uso inadequado dos recursos para tratá-los das moléstias. Naquele momento, além da aprovação do decreto de Henriques de Resende, a Aurora destacava o tratamento dispensado a Pedro II, aludindo que o tutor incutia-lhe medo, tentando fazêlo acreditar que sua vida corria risco nas mãos da Regência:

o augusto menino, quando os regentes dele se aproximavam, estremecia todo, tão convencido estava, pelas intrigas dos que o cercavam, que essa gente queria assassiná-lo, e numa festa na Igreja da Cruz, como fossem chimangos os diretores, não quis sequer tomar um doce, bebendo apenas água vinda do Paço imperial (SOUSA, 1981, p. 99).

No jornal de 14 de março de 1833, publicam-se os nomes de candidatos a deputados cujo nome havia sido manchado na história do país - visto apoiarem a restauração de D. Pedro I, no qual figuram, dentre outros, Antônio de Menezes Vasconcelos Drummond, de Monsenhor Vidigal, Martim Francisco R. Andrada, Antônio Carlos Andrada, Pantoja, de Jacob Niemeyer, Montezuma e Japiassu. Todos estes eram tratados como corcundas, simpáticos ao antigo imperador e afinados às 
maquinações de José Bonifácio.

Outra relação importante do grupo de Aureliano surge na crítica que fazem à aposentadoria forçada de nove desembargadores da relação do Rio de Janeiro, um verdadeiro "golpe de estado, decreto tirânico" (A Verdade, 2 de abril de 1833, p.2). Ao que tudo indica, alguns destes desembargadores haviam sido indicados por Feijó que, fora do governo, viu seus escolhidos serem destituídos. Aureliano era um destes, mas seria reconduzido ao cargo com D. Pedro II. No ano seguinte voltou-se a falar deste assunto, indicando-se o nome dos desembargadores suspensos, responsabilizados por abuso de suas atribuições, devido ao fato de terem exigido prestar fiança no crime cometido por Bento de Antônio Vaia - valido das jovens princesas: Manoel Pinto Ribeiro Pereira Sampaio, Nicolau da Silva Lisboa, Manoel Antônio Galvão, Caetano Maria Lopes Gama e Lúcio Soares Teixeira de Gouveia (A Verdade, 13 de março de 1834, p.2). Com o afastamento de Feijó além daqueles nove magistrados destituídos somaram-se mais cinco.

Em 11 de julho há um artigo sobre a Sociedade Promotora da Instrução Pública da qual fazia parte, dentre outros, Aureliano Coutinho. Outros nomes começam a surgir na folha como opositores do grupo deste, em vários artigos. Assim, novos rivais eram identificados na arena política, em especial, Holanda Cavalcanti, Vasconcelos e Montezuma. Em relação a este último, afirmou-se que procurava junto com o deputado Rebouças negar a existência de uma tentativa de restauração, que isso não passava de um mote do governo para guerrear a oposição (A Verdade, 3 de agosto de 1833, p.3).

No dia 3 de agosto a folha saiu com novo projeto gráfico, com letras garrafais e esboçando novo logotipo, sob o preço de 120 réis. Nela estampava-se a notícia bombástica sobre a recusa do Senado em aceitar o pedido de demissão do visconde de São Leopoldo. Ele queria deixar a Câmara alta, mas não poderia renunciar ao cargo. Uma semana depois, o preço da folha foi abaixado para 80 réis novamente. Pelo visto o aumento não foi bem aceito pelos leitores.

No dia 8 de agosto de 1833 o jornal voltou aos ataques a José Bonifácio. Revela-se que "no dia 2 do corrente deu um baile o sr. Tutor por ocasião do dia natalício da sra. Princesa d. Francisca" no qual uma só e desafinada rabeca animava o ambiente. No mesmo artigo mencionou-se outro baile, dado na Quinta da Joana em homenagem a Pedro II no qual se dizia que este foi constrangido e sua dignidade foi achincalhada (A Verdade, 8 de agosto de 1833, p.2).

Para provocar os restauradores, os articulistas lançaram o mote, em 17 de agosto: "Quem quiser D. Pedro I no trono, que vá morar em Portugal” (A Verdade, 17 de agosto de 1833, p.1). A partir do dia 21 daquele mês o jornal passou a ser publicado na Tipografia Americana e a ser vendido na Livraria Laemmert, na Rua da Quitanda, número 139. No final do mesmo mês, mudouse para a tipografia Miranda e Carneiro, o que indica algum tipo de problema com a impressão da folha. Ou as editoras não comportavam sua publicação ou surgiam questões entre os impressores e 
os assinantes. Talvez outros clientes não concordassem com a publicação de $A$ Verdade em sua tipografia.

O jornal indicou também os administradores da alfândega do Rio de Janeiro: Luiz de Menezes Vasconcelos Drummond e Manoel Caetano, além do irmão de Aureliano, Saturnino de Oliveira, destacando positivamente sua atuação na fiscalização e no combate ao contrabando. Novamente Bonifácio seria alvo de ataques, em artigo que fala sobre o episódio em que o tutor teria feito D. Pedro II decorar um discurso em francês para uma cerimônia em que seriam recebidos representantes do governo francês, mas na hora o monarca mirim se embaraçou e com a saída dos diplomatas, Bonifácio teria dito em presença de funcionários e ministros: "o imperador borrou as calças". Ao que chorou o herdeiro do trono (A Verdade, 27 de agosto de 1833, p.2). O jornal termina dizendo; voltaremos à matéria.

Para não perder seu tom irônico eram desferidos mais ataques aos caramurus e, em um artigo inusitado, cujo título era "Confissão pública de um caramuru arrependido e banhado em lágrimas", fazem pilhérias com a possibilidade da volta de D. Pedro I (A Verdade, 29 de agosto de 1833, p.1). No dia 14 de setembro, um outro artigo procura discutir o desengano da facção restauradora. A folha passa a atacar o jornal Carioca e os caramurus mais incisivamente, por exemplo, em 19 e 24 de setembro, reproduzindo artigo publicado n'O Expositor, que refutava a possibilidade da volta do ex-imperador.

Nova investida a Bonifácio, dessa vez com denúncia ainda mais grave, a respeito da farsa sobre uma suposta trama para sequestrar D. Pedro II. Ali se diz que Bonifácio deveria ser responsabilizado, pois se entendia que ele era

conivente, ou inepto, e certamente ou ele foi conivente com os restauradores na
ridícula farsa que alguns juízes de paz representaram no Paço Imperial na tarde e
noite de 21 do corrente, ou os restauradores servindo-se dele como de um palhaço,
o fizeram representar o entremez do Velho Logrado: acudam, acudam que o
governo manda hoje roubar o menino imperador (A Verdade, 26 de setembro de
1833, p.4).

O mesmo episódio voltou a ser discutido no jornal de $1^{\circ}$ de outubro. Procurava mostrar a que ponto chegava a audácia do tutor, tentando com um ardil ludibriar a opinião pública, colaborando com uma farsa política e incutindo terror no futuro imperador.

Em 8 de outubro, a folha indica que D. Pedro II estava doente e procurou associar seu estado de saúde à conduta do tutor, que o mantinha quase recluso sem passeios e colaborando para piorar sua frágil condição física. No dia 10 do mesmo mês o jornal revela que um médico havia sido chamado para examinar a criança e publica uma nota: "Boletim do estado da moléstia de S. M. o Imperador. Continua a passar sem novidade, tranquilo, mas com febre. 7\10\1833 às 15:20h", assinado por Torres Homem (A Verdade, 10 de outubro de 1833, p.3). 
No mês de outubro vários foram os artigos criticando a Sociedade Militar e exigindo, fazendo eco à Aurora, enérgicas providências contra as tentativas de restauração. Ali se dizia que os caramurus tinham planos para assassinar os regentes e Evaristo da Veiga. Em 11 de novembro, mostra a posição favorável da justiça, com a condenação pelo júri do general Bulow, líder da sedição popular e, no dia 16 outro mostra que o governo suspendeu o juiz de paz João H. Bacelar Pinto Guedes por desobedecer às ordens do governo para reprimir semelhantes motins. No dia 14 de dezembro de 1833 o Paço foi ocupado, diante de vários distúrbios ocorridos nas ruas do Rio de Janeiro. A sede da Sociedade Militar foi depredada (Holanda, 1995, v.4, p. 36).

O jornal passa então a publicar as atas da Sociedade Defensora em 24 e 26 de novembro, avisando sobre um novo golpe: reuniões noturnas da lacaiada de São Cristóvão planejando raptar o imperador e acusar o governo regencial. Por fim, em dezembro, oficiais de justiça tentaram, em vão, solicitar ao tutor que deixasse o palácio e tutoria, como indicava a ordem dos ministros do Império - Chichorro da Gama - e da Justiça - Aureliano Coutinho. A ocasião foi dramática e exigiu a presença de força policial e de dois generais José Joaquim de Lima e Silva e Raimundo José da Cunha Matos que levaram, finalmente, Bonifácio para a reclusão na Ilha de Paquetá.

Em janeiro de 1834 novos artigos são dedicados à Defensora, em um deles, de 25 de janeiro, relembrava-se que a sociedade se posicionou o tempo todo contrária à José Bonifácio na tutoria, acusando-o de "insolência desmedida". Revela-se ainda neles que "o sr. José Bonifácio de Andrada foi suspenso de seu cargo, sem que um só dos seus satélites, guardados em São Cristóvão, se animasse a defendê-lo" (A Verdade, 25 de janeiro de 1834, p.2). Em 6 de fevereiro o jornal mostrou que, acusado de conspiração, Bonifácio havia se recusado a receber o decreto de sua suspensão e que ele tinha armas e militares sob suas ordens (A Verdade, número 272, 1834, p.3). Mas, ameaçado de prisão, visitado por vários soldados e ciente da gravidade da situação, Bonifácio enfim cedeu a 12 de dezembro. Com o êxito de sua causa, os redatores comemoram:

livre o nosso monarca de um tutor, chefe ostensivo da facção desorganizadora que intenta destruir seu trono augusto esta mesma facção reduzida à nulidade e procurando ocultar no pó da terra a vergonha de que se há coberta, o loquaz enviado que haviam dirigido ao anjo redentor, mal com este, porque ousou não obedecer à irresistível eloquência com que o convidava a governar os caramurus do Brasil, nossos inimigos plenamente desmascarados, os perigos que corre a nação, assaz reconhecidos; Exaltados e Moderados, reunidos sob uma só bandeira e prestes a derramar até a última gota de sangue pelo glorioso 7 de abril ( $A$ Verdade, 20 de fevereiro de 1834, número 278, p.1) .

Agora, indicava a folha, o futuro imperador teria um outro tipo de educação. Embora com horários rígidos e previamente determinados, D. Pedro menino "saía, punha-se em contato com o povo, tomava ar, visitava os navios de guerra surtos no porto. E a Aurora, radiante, comenta: 'é assim que os chimangos roubam o menino" (SOUSA, 1981, p. 144). Curioso observar que, a 
despeito das muitas denúncias "Bonifácio foi absolvido, por falta de provas, da acusação de conspiração” (HOLANDA, 1995, v.4, p. 36) e por unanimidade.

O jornal passa a publicar textos sobre "Philosofia Social: o que é a popularidade - amor vago e confuso da multidão". Ocupa quase todo o jornal, sendo publicado somente mais um artigo com notícias de Ouro Preto (A Verdade, 15 de abril de 1834, p.1-4). A ausência de artigos indica que a causa maior defendida pelo periódico havia sido ganha. Ele havia cumprido seu papel. Em 18 de abril é publicado um longo discurso de Torres Homem no Parlamento. A partir de 20 de abril o jornal começa a publicar textos refutando e combatendo falas de d. Pedro I na Europa. Depois faz longa reflexão, em um número inteiro, sobre o 7 de abril (A Verdade, 10 de maio de 1834, p.1). Em seguida publica textos sobre a educação ( 27 de maio), sobre a liberdade (14 de junho), sobre a Cabanagem no Pará, bem como vários trechos do relatório do Ministério da Justiça, pasta cujo titular era Aureliano Coutinho.

No dia 12 de junho de 1834, A Verdade publicou a relação dos votos contra e a favor da destituição de José Bonifácio da tutoria de Pedro II no Parlamento e no Senado. Naquele mês a folha passou a ser impressa na Tipografia de P. Guimarães. O último número saiu em 18 de julho, com a publicação dos rendimentos da alfândega do Rio de Janeiro.

Após vitoriosa campanha, a derrota de Bonifácio abriu caminho, ao lado do combate a exaltados e caramurus, para que os moderados pudessem empreender medidas decisivas, consubstanciadas com o Ato Adicional de 1834, que ficaram conhecidas como o avanço liberal. O triunfo completo de Aureliano Coutinho e de sua facção áulica seria obtido anos depois, quando integraram a causa da Maioridade, contra o grupo de Bernardo Pereira de Vasconcelos e, estranhamente voltaram a se aliar à família de José Bonifácio, pois os irmãos do patriarca juntaramse ao grupo, participando das reuniões na Chácara da Joana de Paulo Barbosa. Aureliano estava, inclusive, casado em segundas núpcias com uma sobrinha-neta do patriarca da Independência. Com o início do Segundo Reinado Aureliano ganhou ainda mais a confiança do jovem imperador D. Pedro II e se tornou uma das figuras de maior projeção na corte até meados de 1848.

\section{Referências Bibliográficas}

A VERDADE, JORNAL MISCELLÂNICO. Rio de Janeiro: Biblioteca Nacional, 1832-4, (2 microfilmes).

ALMEIDA, Tito Franco de. O conselheiro Francisco José Furtado: biografia e estudo de história política contemporânea. São Paulo: Nacional, 1944.

BAENA, visconde de Sanches de. Archivo Heraldico Genealógico. Lisboa: Typographia Universal, 1872. 
brasileiro. Lausanne: Imprimerie La Concorde, 1918.

BARMAN, Roderick J. Uma nobreza do novo mundo: a função dos títulos no Brasil imperial. Mensário do Arquivo Nacional. Rio de Janeiro, v.6, p.4-21, 1973.

BLAKE, Augusto Victorino Alves Sacramento. Diccionario bibliographico brazileiro. Typographia Nacional, Rio de Janeiro, 1893.

BOILEAU. Ouvres. Paris: s.n., 2v., 1821.

BRASIL. Câmara dos Deputados. Anais do Parlamento Brazileiro. Rio de Janeiro: Nacional, 1833.

CALDEIRA, Jorge (org.). José Bonifácio de Andrada e Silva. (Col. Formadores do Brasil). São Paulo: Ed. 34. 2002.

CARVALHO, José Murilo de. Bernardo Pereira de Vasconcelos. São Paulo: Ed.34, 1999.

. D. Pedro II. São Paulo: Companhia das Letras, 2007.

CASTRO, Paulo Pereira de. A “experiência republicana”, 1831-1840. In: HOLANDA, Sérgio B. de. História geral da civilização brasileira. Rio de Janeiro: Bertrand Brasil, 1995, t.2, v.2.

CUNHA, Rui Vieira da. Estudo da nobreza brasileira. Brasília: Ministério da Justiça, 1969.

GUIMARÃES, Lúcia Maria Paschoal. Debaixo da imediata proteção de Sua Majestade Imperial: o Instituto Histórico e Geográfico Brasileiro (1838-1889). RIHGB, v.156, n³88, p.459-613, jul./set., 1995.

HOLANDA, Sérgio Buarque de. História geral da civilização brasileira. Dispersão e unidade. Rio de Janeiro: Bertrand Brasil, 1995, v.4.

MOREL, Marco. Palavras, imprensa e poder. Rio de Janeiro: DP\&A, 2006.

NABUCO, Joaquim. Um estadista do império. Rio de Janeiro: Garnier, 1897.

OTTONI, Teófilo. A circular. Revista do Instituto Histórico e Geográfico Brasileiro, t.78, $2^{\mathrm{a}}$ parte, 1916.

POLIANO, Luís Marques. Heráldica, pág. 372. Ed. GRD. Rio de Janeiro, 1986.

RAMA, Angel. A cidade das letras. São Paulo: Brasiliense, 1982.

SILVA, F. R. A dissolução do gabinete de 5 de maio ou a facção áulica. 2.ed. Rio de Janeiro: Francisco Rodrigues de Paiva, 1901.

SOUSA, Octávio T. de. Evaristo da Veiga. Belo Horizonte: Itatiaia, 1981. . José Bonifácio. Rio de Janeiro: José Olympio, 1972.

WERNET, Augustin. As sociedades políticas (1831-1832). São Paulo: Cultrix, 1978. 


\section{NOTAS}

${ }^{1}$ Esta pesquisa contou com o apoio financeiro do CNPq.

${ }^{2}$ Evidentemente que faço alusão ao clássico: RAMA, Angel. A cidade das letras. São Paulo: Brasiliense, 1982.

${ }^{3}$ Sobre este universo da Corte ver: GUIMARÃES, Lúcia Maria Paschoal. Debaixo da imediata proteção de Sua Majestade Imperial: o Instituto Histórico e Geográfico Brasileiro (1838-1889). RIHGB, v.156, n³88, p.459-613, jul./set., 1995; BLAKE, Augusto Victorino Alves Sacramento. Diccionario bibliographico brazileiro. Typographia Nacional, Rio de Janeiro, 1893; BAENA, visconde de Sanches de. Archivo Heraldico Genealógico. Lisboa: Typographia Universal, 1872; POLIANO, Luís Marques. Heráldica, pág. 372. Ed. GRD. Rio de Janeiro, 1986; CUNHA, Rui Vieira da. Estudo da nobreza brasileira. Brasília: Ministério da Justiça, 1969; BARMAN, Roderick J. Uma nobreza do novo mundo: a função dos títulos no Brasil imperial. Mensário do Arquivo Nacional. Rio de Janeiro, v.6, p.4-21, 1973; BARÃO DE VASCONCELOS; BARÃO SMITH DE VASCONCELOS. Archivo nobiliarchico brasileiro. Lausanne: Imprimerie La Concorde, 1918.

${ }^{4} \mathrm{Na}$ ocasião de sua morte, D. Pedro II cogitou conceder-lhe título póstumo, mas foi contido por seus próximos, que lhe reiteraram o fato de que Bonifácio jamais havia pleiteado honrarias nobiliárquicas em vida.

${ }^{5}$ Só o belo é verdadeiro, só o verdadeiro é agradável. Ele deve reinar em toda parte, mesmo na fábula. Trata-se de um trecho da obra de Boileau, Epístola IX, Ouvres. Paris: s.n., 1821, v.2, p.111.

${ }^{6}$ Circulou entre 10 de dezembro de 1831 e 22 de fevereiro de 1832.

${ }^{7}$ Que tinha como epígrafe: "Jamais pour s'agrandir, vit on, dans sa manie, un tigre en factions partager l'Hyrcaine?" de Boileau. Seus redatores eram o barão de Bulow, Martim Francisco e Antonio Carlos Andrade. Circulou entre 1832 e 1833.

${ }^{8}$ Sua epígrafe era "Soyez moderes, seyez justes!” e circulou entre 1832 e 1833.

${ }^{9}$ Trata-se do A Matraca dos Farroupilhas que circulou no Rio de Janeiro entre novembro de 1831 e março de 1832 , e, cuja epígrafe era "Em sendo por mão destra maneada, vence mais a matraca do que a espada".

${ }^{10}$ Circulou entre 1831 e 1833. Reapareceu em 15 de abril de 1835. Sua epígrafe era "Todos os Brasileiros são obrigados a pegar em armas, para sustentar a Independência, e integridade do Império, e defendê-lo dos seus inimigos externos, ou internos" extraída da Constituição de 1824.

${ }^{11}$ Nova Luz Brazileira que circulou entre dezembro de 1829 e outubro de 1831.

${ }^{12}$ Clarim da Liberdade, que circulou entre 12 de novembro de 1831 e junho de 1833. Sua epígrafe era "Os povos proscrevem aos depostas, mas não ao despotismo", do conde de Volney (1757-1820).

${ }_{13}$ Além de Bonifácio, contam entre os fundadores Antônio Borges da Fonseca, Francisco de Lima e Silva, José da Costa Carvalho, Venâncio Henriques de Rezende e Martim Francisco, irmão de José Bonifácio.

${ }^{14}$ Circulou de 1832 a 1834, sua epígrafe era "Verdade e lei".

15 "Esses que se lembram no Brasil do meu nome para fazerem outra bernarda, sempre são bem asnos". Discurso de Cunha Matos. BRASIL. Câmara dos Deputados. Anais do Parlamento Brazileiro. Rio de Janeiro: Nacional, 1833, tomo 2, p.48.

${ }^{16}$ Circulou de março de 1832 a abril de 1833, e tinha duas epígrafes: "Eu não falo senão verdades puras", de Camões e "Falai, em tudo, verdades a quem, em tudo, as deveis" de Sá de Miranda. Seu redator era David Fonseca Pinto.

${ }^{17}$ Aurora Fluminense de Evaristo da Veiga que circulou de 1835 a 1839.

${ }^{18}$ Circulou de 1826 a 1832, seus redatores eram Antonio Jose do Amaral e Jose Joaquim Vieira Souto.

${ }^{19}$ Circulou de 1831 a 1833 e seu proprietário era Joaquim José Rodrigues Torres.

${ }^{20}$ Circulou de 1823 a 1833 e seus redatores eram frei Francisco de Santa Teresa de Jesus Sampaio (1824-1825) e nos últimos anos o padre Januário da Cunha Barbosa.

${ }^{21}$ Circulou de outubro de 1831 a abril de 1832.

${ }^{22}$ Circulou de 1830 a 1832.

${ }^{23}$ O Homem e a América: jornal da sociedade defensora da liberdade e independêcia nacional do Rio de Janeiro, circulou de 1831 a 1833 .

${ }^{24}$ O Mensageiro da Câmara dos Deputados, que circulou a partir de 1831 até 1832.

${ }^{25}$ Circulou de 1831 a 1832.

${ }^{26}$ Circulou apenas em 1832.

${ }^{27}$ Circulou entre 1833 e 1836, propriedade de Domingos Jose Pires de Miranda.

Artigo recebido em 02/2010. Aprovado em 05/2010. 